\title{
Working
}

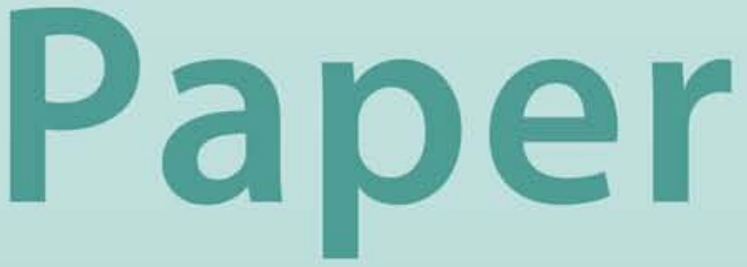




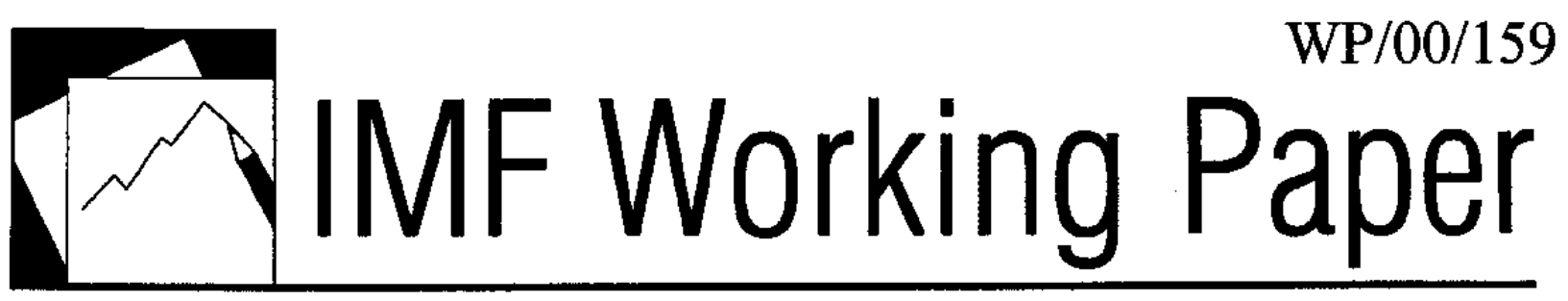

\title{
An Interest Rate Defense of a Fixed Exchange Rate?
}

\author{
Robert P. Flood and Olivier Jeanne
}




\title{
IMF Working Paper
}

\author{
Research Department
}

\author{
An Interest Rate Defense of a Fixed Exchange Rate? \\ Prepared by Robert P. Flood and Olivier Jeanne ${ }^{1}$ \\ Authorized for distribution by Peter Clark
}

October 2000

\begin{abstract}
The views expressed in this Working Paper are those of the author(s) and do not necessarily represent those of the IMF or IMF policy. Working Papers describe research in progress by the author(s) and are published to elicit comments and to further debate
\end{abstract}

Defending a government's exchange-rate commitment with active interest rate policy is not an option in the Krugman-Flood-Garber (KFG) model of speculative attacks. In that model, the interest rate is the passive reflection of currency-depreciation expectations. In this paper we show how to adapt the KFG model to allow for an interest rate defense. It is shown that increasing the domestic-currency interest rate makes domestic assets more attractive according to an asset substitution effect, but weakens the domestic currency by increasing the government's fiscal liabilities. As a result, raising the interest rate hastens the speculative attack when speculation is motivated by underlying fiscal fragility.

JEL Classification Numbers: F32, F33

Keywords: Speculative attack, fixed exchange rate regime, fiscal policy

Author's E-Mail Address: rflood@imf.org, ojeanne@imf.org

\footnotetext{
${ }^{1}$ This paper benefited from comments by seminar participants at the IMF, UCSC, UC Berkeley and by Michael Dooley, Peter Garber, Nancy Marion, Richard Portes and Andrew Rose.
} 


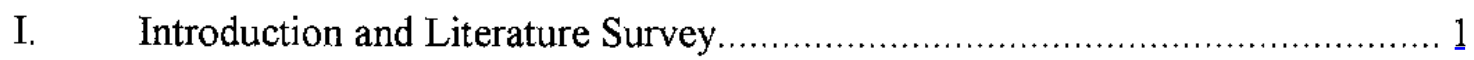

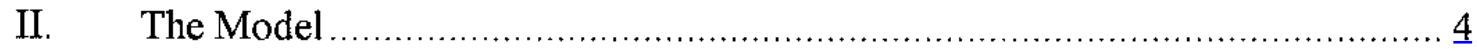

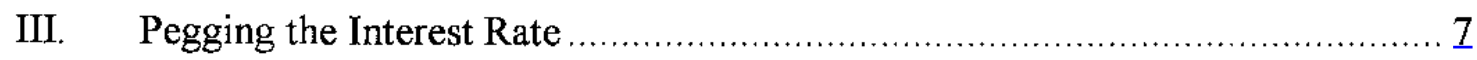
A. The Pre-Collapse Regime
B. The Post-Collapse Regime ............................................................... 2
C. The Collapse ....................................................................... 10
D. Multiple Equilibria ............................................................ 12

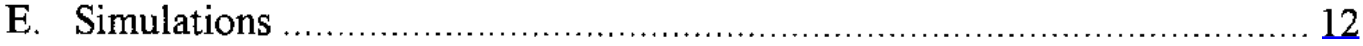
F. Is This Model Helpful for Interpreting the 1990s Asian Crisis................ 13

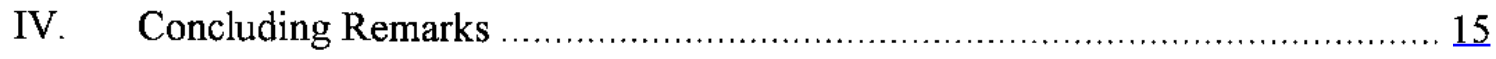

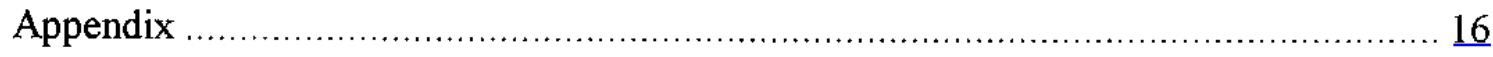

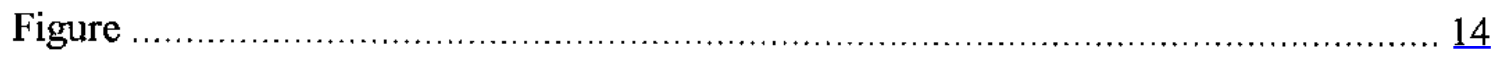

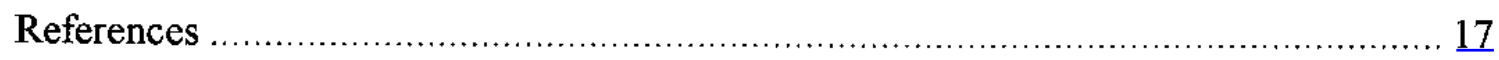




\section{INTRODUCTION AND LITERATURE SURVEY}

This paper is about the possibility of an active interest-rate defense in the KrugmanFlood-Garber (KFG) model of speculative attacks. ${ }^{2}$ It is straightforward to see that this requires a departure from uncovered interest parity (UIP), which was a basic KFG building block. UIP implies that the domestic-currency interest rate is the passive reflection of devaluation expectations. There is, therefore, no room for active interest rate policy.

A policy-responsive wedge must be driven into the interest parity condition. Readers are used to risk aversion implying such a wedge and this is one entrée to the problem. A good bit of progress on interest rate policy is possible, however, in an environment of certainty so we will forgo uncertainty for now. ${ }^{3}$ We bring in our wedge by assuming domestic and foreign bonds to be imperfect substitutes in a convenient way that allows the domestic monetary authorities room to maneuver in setting the interest rate. This defines the program of the paper: solving a generalized version of the KFG model in which domestic and foreign bonds are imperfect substitutes and the domestic-currency interest rate is one of the variables controlled by domestic monetary policy.

Our goal is to find the scope for policy tradeoffs involving a number of potential policy tools - interest rates, nominal-liability growth (money and bonds), the real government deficit and international reserve management all as they arise in the KFG model. We evaluate policies - on an equal footing - in terms of how long the policies preserve a given fixed exchange rate. This analysis is supported by numerical simulations parameterized with data from Mexico in the 1990s. We also apply the model in a heuristic way to the East Asian crises of the late 1990s.

There have been policy debates recently over the efficacy of defending exchange rates using the interest rate, and they have spurred a literature that is closely related to the present paper ${ }^{4}$ At the empirical level, Furman and Stiglitz (1998) find, in a small set of episodes of crises in nine emerging markets, that interest rate hikes are associated with exchange rate depreciations. Kraay (1999), considering a larger sample of speculative attacks in developed and developing economies, concludes to a lack of systematic correlation between interest rates and the outcome of speculative attacks. Goldfajn and Baig (1998) do not find any robust correlation between interest rates and exchange rates in the recent crises in Southeast Asia. Overall, the evidence presented in these papers is difficult to interpret as a systematic lack of efficacy of interest rate defenses, given the obvious reverse causality and

\footnotetext{
${ }^{2}$ See Krugman (1979) and Flood and Garber (1984b).

${ }^{3}$ Krugman (1979) was conducted in certainty as was the first section of Flood and Garber (1984b).
}

${ }^{4}$ See Lane et al (1999), chapter 6, for a review of this nascent literature. 
endogeneity problems, but at least suggests that the link between the level of interest rates and the credibility of the currency is not systematic and depends on the circumstances. Thus theoretical work may be useful in identifying the circumstances in which an interest rate defense can work and those in which it does not.

Recent theoretical papers studying the efficacy of interest rate defenses of fixed currency pegs include Bensaid and Jeanne (1997), Drazen (1999) and Lahiri and Végh (1999). The first two papers belong to the "second generation" or "escape clause" approach to currency crises. Bensaid and Jeanne's (1997) paper was motivated by the 1992-3 crisis of the European Monetary System; it formalizes the point that raising the interest rate may be a self-defeating strategy because of the harm it inflicts on the economy, and can make speculation against the currency self-fulfilling. Drazen (1999) presents a framework in which the government chooses between two defense strategies, raising the interest rate or borrowing reserves. One important aspect of this decision-in Drazen's setup-is that it signals to the market some unobservable characteristics of the government, such as the availability of reserves or the government's resolve to defend the currency. Drazen shows that depending on the precise informational structure, raising the interest rate might send a good signal and enhance the credibility of the fixed peg.

The present paper is more closely related to Lahiri and Végh (1999), who, like us, adopt a KFG-type framework and stress the fiscal implications of an interest rate defense. Lahiri and Végh find that the link between the level of interest rates and the timing of the attack is non-monotonic: an interest rate rise might delay the attack if it is small, but hasten it if it is large. This stems in part from the menu of assets available to households in their model: they introduce a new asset, "liquid bonds", which, on the one hand is assumed to be part of broad money together with cash holdings, but on the other hand pays interest - though not the same as regular bonds. Thus an interest rate defense (defined as a rise in the interest rate on liquid bonds) increases money demand, which contributes to delay the attacks. Like in our model, this also increases fiscal liabilities, with an opposite effect. Because money demand has been kept standard in our model only the second effect is present.

\section{THE MODEL}

We study a small open economy in continuous time. There is one homogeneous global good and the Law of One Price applies at all times, making the domestic price level equal to exchange rate (the foreign price level is constant and normalized to 1). 
The first group of equations is almost the same as in KFG. These are the equations for money demand, interest rate parity, the central bank balance sheet, and the reserves constraint.

$$
\begin{aligned}
& \frac{M_{t}}{S_{t}}=\mu \exp \left(-\alpha r_{t}\right) \\
& r_{t}=r^{*}+\frac{\dot{S_{t}}}{S_{t}}+\theta \frac{B_{t}}{S_{t}} \\
& M_{t}=D_{t}+S_{t} R_{t}^{*} \\
& R_{t}^{*} \geq 0
\end{aligned}
$$

In levels, $M$ is domestic-currency high power money; $S$ is the exchange rate defined as the domestic-currency price of foreign exchange; $r$ is the domestic-currency interest rate and $r^{*}$ is the foreign-currency analog (assumed to be constant); $B$ is world-wide private holding of domestic-government domestic-currency debt; $D$ is domestic credit (government bonds) held by the domestic central bank, and $R^{*}$ is domestic central bank holding of foreign currency debt.

The only difference from KFG is the term $\theta B / S$ in the interest parity condition. This term captures the idea that domestic and foreign bonds are imperfect substitutes. It is positive (by assumption) and increasing with the quantity of domestic bonds in international investors' portfolios. ${ }^{5} \mathrm{KFG}$ is obtained for $\theta=0$. Then, the equilibrium is pinned down by the specification of an exogenous path for domestic credit, $D$. This is no longer true if $\theta>0$ because there is nothing in equations (1)-(4) to determine supplies and demands for domestic bonds.

\footnotetext{
${ }^{5}$ Our justification for a wedge in UIP is the assumption that domestic and foreign-currency bonds are imperfect substitutes in agents' portfolios. At a deeper level, imperfect substitution may reflect a utility-based bias toward own-currency assets that could be derived from those assets having a liquidity advantage over foreign-currency assets (see Lahiri and Végh, 1999). The wedge could equally well result from increasing marginal domestic-currency borrowing cost (see Drazen, 1999). The function we use here is derived from risk aversion in Jeanne and Rose (1999). In the first version of this paper we used a formulation, derived from Flood and Marion (2000), where the wedge was proportional to the ratio of domestic bonds to foreign bonds in investors' portfolio-and we obtained similar results.
} 
We close the expanded model by introducing the domestic government's budget constraint, and one other accounting identity.

$$
\begin{aligned}
& \dot{N}_{t}=r_{t}\left(N_{t}-D_{t}\right)-r^{*} S_{t} R_{t}^{*}-S_{t} \tau \\
& N_{t}=B_{t}+D_{t}
\end{aligned}
$$

The government's budget constraint (consolidated) determines the evolution of the total stock of outstanding domestic nominal bonds, $N$. According to equation (5), $N$ grows in pace with the government's net deficit; $r(N-D)$ gives net interest payments of the consolidated government; interest payments to the domestic government on international reserve holding are $r * S R^{*}$, and the real level of taxes is $\tau$, which may be either positive or negative. Throughout the paper we take $\tau$ as exogenous and constant. ${ }^{6}$ In equation (6) all domestic government bonds must be held either by the world private sector or by the domestic monetary authority.

In all of our work, the monetary authority fixes the exchange rate at $\bar{S}$ as long as international reserves are above an exogenous lower bound, set at zero. When reserves are exhausted the exchange rate floats. The survival of the fixed-rate regime depends on the behavior of the post-collapse floating exchange rate. Let $\widetilde{S}$ be the shadow exchange rate, which is defined to be the flexible exchange rate that would prevail if the fixed rate regime were attacked successfully. As usual, the fixed-rate regime survives until attack is worthwhile to speculators, i.e., $\tilde{S} \geq \bar{S}$. In the current perfect foresight setting, an anticipated attack takes place when $\tilde{S}=\bar{S}$.

KFG relies on the assumption that domestic credit grows at the same rate, $g$, before and after the collapse, and does not jump at the time of the collapse. If $\theta=0$, the collapse time $T$ is the solution to the standard formula: ${ }^{7}$

$$
\frac{D_{0} \exp (g T)}{\bar{S}}=\mu \exp \left(-\alpha\left(r^{*}+g\right)\right)
$$

This equation says that money demand is equal to money supply at the time of the collapse. Increasing the growth rate in domestic credit hastens the collapse of the fixed peg.

\footnotetext{
${ }^{6}$ Holding $\tau$ constant is a simplification that allows us to divorce asset-market effects of interest rate policy from associated fiscal reform.

${ }^{7}$ We insert this formula as a point of comparison for our later result in equation (16).
} 
When $\theta>0$ the dynamics of the economy become more complicated, but KFG's results still hold for $\theta$ small enough (by continuity).

An active interest rate defense policy is impossible in the standard KFG model (with $\theta=0)$ since UIP implies that the domestic interest rate must remain equal to its foreign counterpart before the collapse of the currency peg. ${ }^{8}$ The wedge in the interest parity condition that we have introduced in the model, on the other hand, gives the authorities an additional degree of freedom in setting the interest rate. Can it be used to postpone-or forestall-the crisis? This is the question we address in the following section.

\section{Pegging THE INTERest Rate}

We assume, for simplicity, that the interest rate is constant before and after the attack, but may jump at the time of the attack: the pre-attack interest rate is set at $\bar{r}$ and the postattack interest rate is set at $\overline{\bar{r}}$ :

$r_{t}=\bar{r}, \quad t \leq T$

$r_{t}=\bar{r}, \quad t>T$

We make no assumption about the relative interest rate levels before and after the collapse. The government primary surplus, $\tau$, is constant.

\section{A. The Pre-Collapse Regime}

While both the exchange rate and the interest rate are fixed, the domestic monetary authority intervenes in the domestic bond market and in the foreign exchange market to fix prices. It is no surprise then that with prices fixed, quantities adjust to achieve equilibrium. Asset market equilibrium is characterized by:

$$
r_{t}-r^{*}=\theta \frac{B_{t}}{\bar{S}}=\theta \frac{\left(N_{t}-M_{t}+\bar{S} R_{t}^{*}\right)}{\bar{S}}
$$

with $M_{t}$ constant, equal to $M=\bar{S} \mu \exp (-\alpha \bar{r})$. Foreign exchange reserves, $R^{*}$, move to clear the market. Consider the effect of an increase in the foreign interest rate, $r^{*}$; it

\footnotetext{
${ }^{8}$ This is because the standard KFG model is deterministic. Stochastic extensions of this model, such as in the second part of Flood and Garber (1984b) or Obstfeld (1986), produce a peso effect before the collapse. In these models, however, UIP holds. The interest rate differential remains the passive reflection of devaluation expectations, not the result of an active interest rate defense.
} 
increases the demand for foreign-currency assets, which requires a fully sterilized balancing reserve outflow to accommodate the private portfolio shift at a fixed exchange rate. An increase in $r$, on the other hand, induces a different balancing operation where the domestic monetary authority purchases international reserves, but more than fully sterilizes the purchase in order to accommodate reduced money demand. ${ }^{9}$

In equation (8), the dynamics of $R^{*}$ are determined by the dynamics of $N$. At the attack time, $R^{*}$ will jump to preserve asset market equilibrium and avoid a foreseen exchange rate jump. Asset rates of return jump from pre- to post-attack levels but not the exchange rate. A foreseen exchange rate jump would present a risk-free profit opportunity. In certainty, the attack time is determined to ensure no foreseen profits.

With prices and the primary fiscal deficit fixed, debt dynamics become a simple accounting problem. Pre-collapse debt dynamics of debt are given by:

$$
N_{t}=\left(N_{0}+\lambda\right) \exp \left(r^{*} t\right)-\lambda
$$

where $\lambda$ is:

$$
\lambda=\left(\frac{\left(\bar{r}-r^{*}\right)^{2}-\theta \tau}{\theta r^{*}}-\mu \exp (-\alpha \bar{r})\right) \bar{S}
$$

(see the appendix). The variable $\lambda$ is strictly increasing with $\bar{r}$ and strictly decreasing with $\tau$. Hence, given $N_{0}$, the level of nominal debt at any given time $t>0$ before the speculative attack is strictly increasing with the interest rate and strictly decreasing with real tax receipts.

$$
\forall t \in(0, T), \quad \frac{\partial N_{t}}{\partial r}>0 \quad \frac{\partial N_{t}}{\partial \tau}<0
$$

This is sensible. An increase in the interest rate on debt will increase the rate at which debt is accumulated and an increase in taxes will decrease debt accumulation-other things held constant.

${ }^{9}$ This statement assumes $(1 / \theta)+\partial m / \partial r>0$, which ensures that increasing $r$ raises the net demand for domestic-currency denominated assets. 


\section{B. The Post-Collapse Regime}

Following a collapse, the economy settles (immediately) into a real steady state with constant rates of depreciation, nominal expansion and a constant real level of government debt. ${ }^{10}$ The way public finance works presently is that the economy jumps from the insufficiently-financed fixed-rate equilibrium that is destined to collapse to an inflationary steady state. As we have assumed the primary surplus, $\tau$, to be constant and since seignorage is determined by $\overline{\bar{r}}$, the only remaining balancing variable is the real level of debt, $n=N / S$, which must satisfy:

$$
n\left(r^{*}+\theta(n-m)\right)=\stackrel{=}{r} m+\tau
$$

where $m=\mu \exp (-\alpha \vec{r})$ denotes the real quantity of money in the post-collapse regime (see the appendix). Equation (12) is the steady state $(\dot{n}=0)$ government's budget constraint with private behavior incorporated and international reserves set at the post-crisis lower bound, zero. This equation says that the (real) service of government debt must equal seignorage revenues - in the form in the interest rebate from the monetary authority to the treasuryplus net fiscal receipts on the primary account.

Equation (12) is a second-order polynomial equation in $n$, whose unique positive root is a function of the interest rate and fiscal receipts:

$$
n=\nu(\bar{r}, \tau) \equiv \frac{1}{2}\left\{-\frac{\left(r^{*}-\theta m\right)}{\theta}+\sqrt{\frac{\left(r^{*}-\theta m\right)^{2}}{\theta^{2}}+\frac{4(r m+\tau)}{\theta}}\right\}
$$

If $\theta=0$ the interest parity wedge disappears and $v($.$) takes the simple form:$

$$
v(\bar{r}, \tau)=\frac{=\bar{r} \mu \exp (-\alpha \bar{r})+\tau}{r^{*}}
$$

which is increasing in the level of tax receipts, $\tau$, and in the interest rate, $\bar{r}$, when the economy is on the increasing branch of the seigniorage Laffer curve, i.e., if the interest rate is lower than $1 / \alpha$. If $\theta>0$ things are a bit more complicated (see the appendix) but it remains true that:

${ }^{10}$ This is where we rule out post-collapse hyperinflationary bubbles and government Ponzi schemes. Without ruling out such anomalies, the timing of collapse is arbitrary. See the appendix for details and see Flood and Garber (1984b) for a discussion of this issue. 


$$
\frac{\partial v}{\partial \tau}>0
$$

An increase in taxes allows the government to support higher steady state debt. The steady state level of debt is also increasing with the nominal interest rate when the latter is not too high:

$$
\frac{\partial v}{\partial r}>0 \text { iff } \quad r<\frac{1}{\alpha}-\theta v
$$

An increase in the nominal interest rate increases both the rate of inflation and the real interest rate. The real interest rate must increase to accommodate the shift of domestic bonds from the central bank to investors which is induced by lower money demand. The impact of a nominal interest rate increase on the government deficit thus involves two opposite effects: on the one hand the real service of debt increases but on the other hand, the government's income is increased by additional seigniorage revenue. Equation (15) says that the second effect dominates if the slope of the seignorage Laffer curve is large enough. In the following we assume this condition to be satisfied.

\section{The Collapse}

The shadow exchange rate at time $\mathrm{t}, \widetilde{S}_{t}$, is the value of the exchange rate such that

$$
\frac{N_{t}}{\widetilde{S}_{t}}=v(\overline{\bar{r}}, \tau)
$$

For given post-collapse policies, $\widetilde{S}$ is proportional to the state variable $N_{t}$. If $N$ starts small but grows without bound then the fixed rate is doomed. The currency peg collapses if and when the shadow exchange rate crosses the fixed peg, i.e., if there is a time $T$ such that:

$$
\frac{\left(N_{0}+\lambda\right) e^{r * T}-\lambda}{\bar{S}}=v(\bar{r}, \tau)
$$

The collapse is inevitable if nominal debt explodes, i.e., if $N_{0}+\lambda>0$. In that case the time of collapse is given by equation (16). Several observations are in order.

First, the collapse is essentially the reflection of fiscal imbalance. ${ }^{11}$ It is always possible, other things equal, to raise the level of taxes such that $N_{0}+\lambda<0$, which prevents public debt from exploding. The most natural way to defend the currency peg is to fix the underlying fiscal problem.

${ }^{11}$ In this sense the model is in the spirit of the fiscal extensions of the KFG framework, see e.g. Buiter (1987). Daniel (2000) recasts the argument in the context of Woodford's (1995) "fiscal theory of the price level." Our argument is indebted especially to Sargent and Wallace (1981). 
Second, the model is set up to see if the same result can be achieved using the interest rate. ${ }^{12}$ Changing $\bar{r}$ and $\bar{r}$ will affect both the left and right-hand sides of equation (16), possibly postponing the collapse-or even removing its occurrence if the equation no longer has a solution. It is easy to see from (16) that the time of the collapse is decreasing with the precollapse interest rate and increasing with the post-collapse interest rate:

$$
\frac{\partial T}{\partial \bar{r}}<0 \quad \frac{\partial T}{\partial \bar{r}}>0
$$

Raising the interest rate before the attack, and lowering it afterwards, only hastens the collapse of the currency peg. This result is intuitive from the underlying fiscal nature of the crisis. Raising the interest rate before the collapse worsens the government's fiscal problem, since it amounts to financing a stock of low-interest-rate-bearing foreign assets by borrowing at a high interest rate. ${ }^{13}$ On the other hand, higher interest rates after the collapse are associated with higher seigniorage revenues, allowing the government to service a larger real debt in steady state. Before the collapse an increase in the nominal interest rate makes the fiscal situation worse because it is reflected one-for-one in the real interest rate (since the price level is constant); after the collapse the same increase in the nominal interest rate improves the fiscal situation by raising the inflation rate, and seigniorage revenues.

An interest rate policy involving a high interest rate before an attack - perhaps as an ill-conceived incentive to speculators to hold domestic currency assets-and a lower rate following the attack is self-defeating. While such a policy makes reserves look good before the collapse, those reserves are not reliably positive indicators of the health of the fixed rate regime. The only reliable indicator of the health of the fixed rate is the level of government debt, assuming a constant fiscal deficit. Reserves are expensive window dressing here; by accumulating them the government behaves as an insolvent household that would try to impress creditors by financing large cash balances with credit card debt.

Our results are strong and surprisingly clear. In the concluding remarks that follow the next sections we will discuss the assumptions crucial to those results, in particular that international reserves are inherently useless.

\footnotetext{
${ }^{12}$ In our constant interest rate assumption we have allowed simplicity to preclude the optimal interest rate policy - the one that would maximize the length of the fixed rate epoch. The optimal policy minimizes pre-attack debt accumulation subject to $R^{*} \geq 0$ with the post attack interest rate set to maximize seignorage.

${ }^{13}$ Such an effect was at work in Brazil in 1998, according to some commentators.
} 


\section{Multiple Equilibria}

An ill-conceived interest rate strategy not only hastens the collapse, but also can make it self-fulfilling. The collapse time is an endogenous variable and the attack itself may influence government policy. The attack signals the policy to change from $\bar{r}$ to $\overline{\bar{r}}$, which is just the sort of Salant-style policy nonlinearity that may induce multiple equilibria. ${ }^{14}$ To see this point rewrite the shadow rate at $t$ as:

$$
\widetilde{S}_{t}=\frac{N_{t}}{\frac{\{v(\overline{\bar{r}}, \tau)-v(\bar{r}, \tau)\}}{\Delta r} \Delta r+v(\bar{r}, \tau)}
$$

Normally $\frac{\{v(\overline{\bar{r}}, \tau)-v(\bar{r}, \tau)\}}{\Delta r}>0$ as studied in the derivative above. A decrease in the interest rate, $\Delta r<0$, after the attack, will, therefore increase the shadow rate. This is precisely the condition that can make a speculative attack self-fulfilling. The attack induces the very policy change that ratifies the attack.

\section{E. Simulations}

The dynamics of speculative attacks can be illustrated with the help of simulations. Figure 1 shows the dynamics of the exchange rate, money supply and its components before and after a speculative attack. The figure was constructed with the following calibration: $\alpha-1, \theta=1 /(2 \mu), N_{0}=\mu / 2, \tau=0, \bar{r}=20 \%, \bar{r}=10 \%$ and $r^{*}=5 \%$. The fixed parity, $\bar{S}$, was normalized to 1 and $\mu$ was treated as a scaling parameter (it was set to 1 in the figure). The calibration of the structural parameters $\alpha$ and $\theta$ was derived from Mexican data in the early 1990 s. $^{15}$

${ }^{14}$ This type of multiplicity was pointed out in Flood and Garber (1984a) following comments made by Steven Salant. Obstfeld (1986) pioneered using the idea in the exchange rate context where it has had a large following; see Flood and Marion (1999) for a survey.

15 The value of 1 for the interest rate semi-elasticity of money demand is in line with estimates obtained in the literature (Cuthbertson and Galindo, 1999). Parameter $\theta$ is the increase in the domestic interest rate that is required to attract one unit of foreign capital. Its calibration is based on Werner's (1996) finding that in the two years leading to the 1994 Mexican peso crisis, increasing the share of peso-denominated debt (CETES) in total debt (CETES+TESOBONOS) required a 0.25 percentage point increase in the interest rate on one-month CETES. In 1992-93 total debt (CETES+TESOBONOS) amounted to approximately $20 \mathrm{US} \$$ bn and M1 to approximately $40 \mathrm{US} \$$ bn. Hence the dollar reserves attracted by a 1 percentage point rise in the one-month peso interest rate can be estimated to 4 percent of total debt, or 2 percent of $\mathrm{Ml}$, implying $1 \%=02 \% \mu$, or $\theta=1 /(2 \mu)$. 
Figures 1B-C highlight the similarities and the differences between KFG and our model. Like in KFG, the exchange rate shifts without discontinuity from the fixed parity to a path with a constant rate of depreciation, while reserves jump down to zero, at the time of the attack. Unlike in KFG, money supply jumps up because of the decrease in the interest rate. Domestic credit also jumps up, so as to equate money supply and money demand at the postcollapse interest rate.

The impact of the interest rate policy on the date of collapse is illustrated in Table 1. The table gives the time of collapse for different values of the pre-attack and post-attack interest rates (under the same calibration as in the figure). It appears that in accordance with our theoretical results, lowering the interest rate before the attack lengthens the life of the currency peg. This effect, moreover, is quite substantial. When the pre-attack interest rate falls below 15 percent the fixed peg becomes fiscally sustainable in the long term, so that there is no speculative attack. Increasing the post-attack interest rate lengthens the life of the fixed peg, but less substantially.

Time of the Attack for Different Values of the Pre-Attack and Post-Attack Interest Rate

\begin{tabular}{lllll}
\hline Pre-Attack Interest Rate $=$ & $14 \%$ & $16 \%$ & $18 \%$ & $20 \%$ \\
Post-Attack Interest Rate & & & & \\
\hline $10 \%$ & $+\infty$ & 30.96 & 17.78 & 12.19 \\
$12 \%$ & $+\infty$ & 31.33 & 18.06 & 12.41 \\
$14 \%$ & $+\infty$ & 31.66 & 18.31 & 12.60 \\
$16 \%$ & $+\infty$ & 31.95 & 18.52 & 12.77 \\
$18 \%$ & $+\infty$ & 32.20 & 18.71 & 12.92 \\
$20 \%$ & $+\infty$ & 32.42 & 18.88 & 13.05 \\
\hline
\end{tabular}

\section{F. Is This Model Helpful for Interpreting the 1990s Asian Crises? ${ }^{16}$}

Yes, but it leaves out a crucial part of the story. In the model, fiscal problems lead to currency crises and effective long-term currency-peg defense is a fiscal issue. In the East Asian crises of the late 1990's countries' on-book fiscal positions were strong and monetary policy was not excessively expansionary $(B e r g, 1999)$. Many of the countries that went into currency crisis experienced problems, however, in the heavily extended banking and private corporate sectors.

${ }^{16}$ This section has benefited from discussions with Michael Dooley, Peter Garber and Nancy Marion. 
Figure 1A: Interest Rate

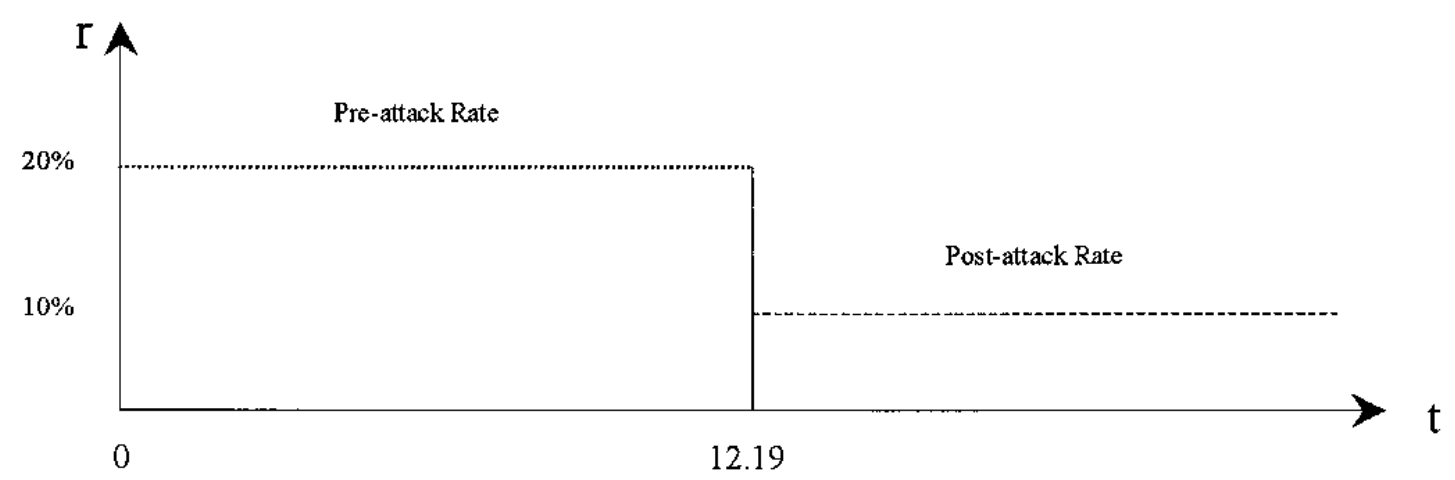

Figure 1B: Exchange Rate

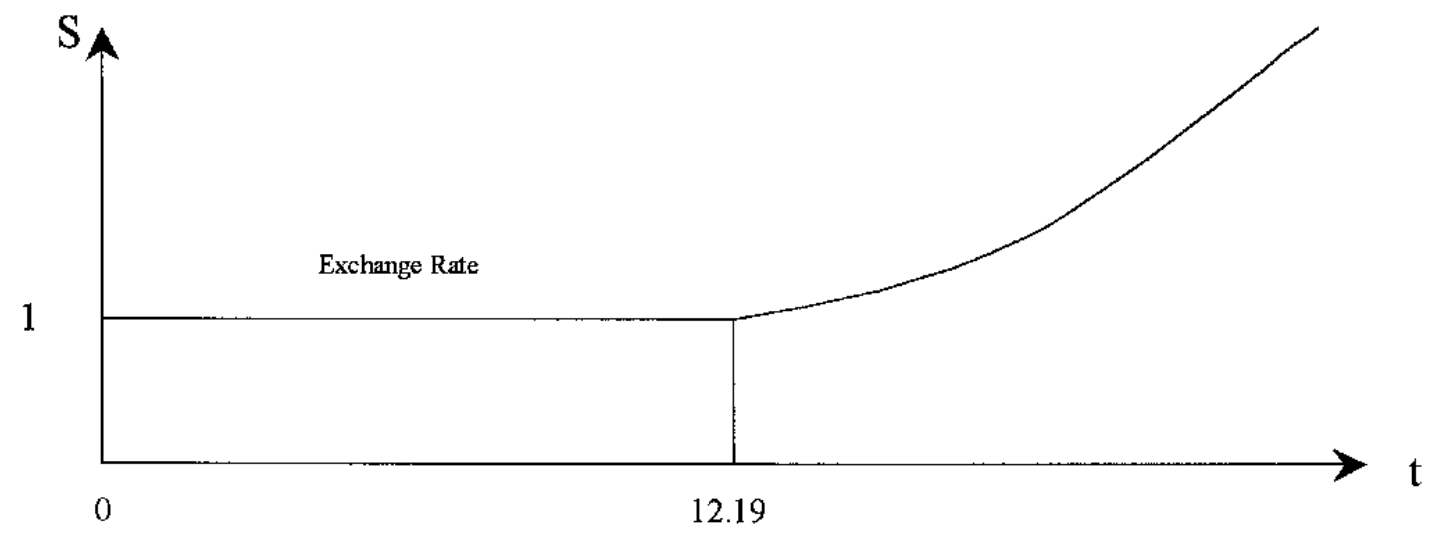

Figure IC: Money Supply and Its Components

\section{$\mathbf{M}, \mathbf{D}, \mathbf{S R}^{*}$}

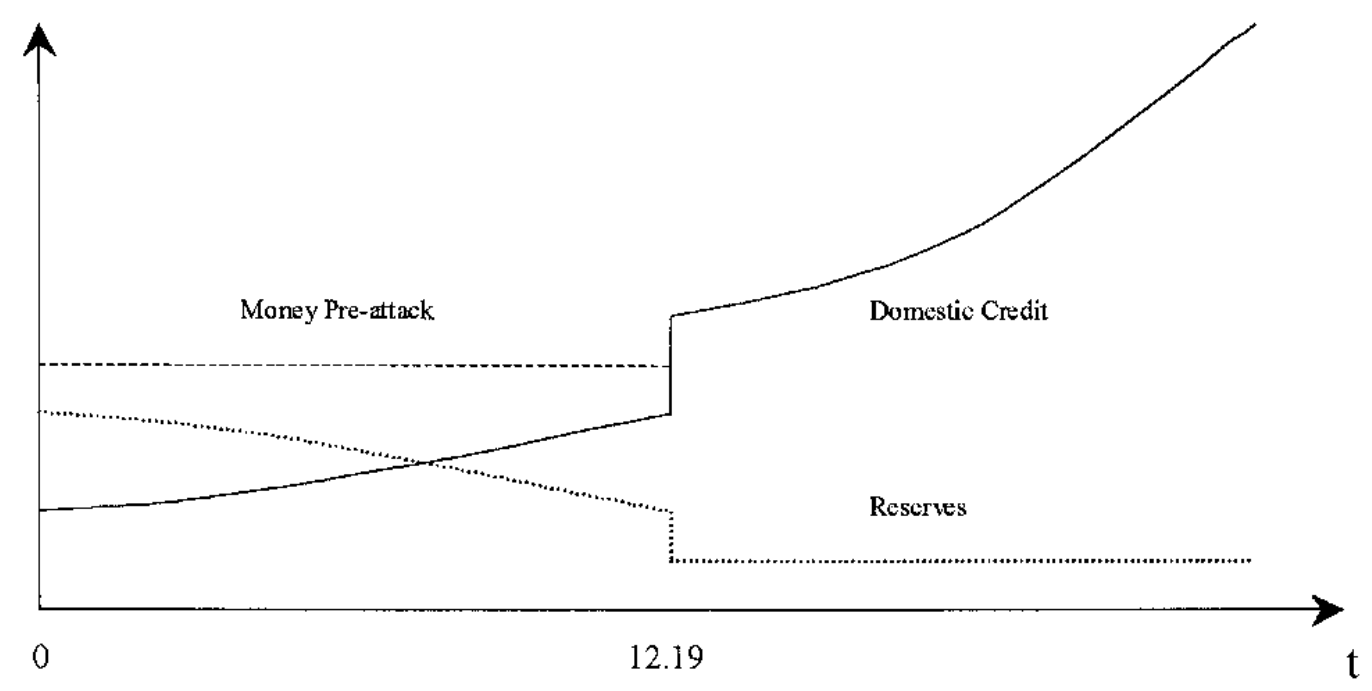


In expanded KFG, the only way banking collapse and private-sector failures translate into a currency-peg collapse is if the private sector believes that off-book government-bailout promises suddenly increased effective government debt (Burnside, Eichenbaum and Rebelo, 1998). If perceived government debt jumps unexpectedly, the shadow exchange rate jumps unexpectedly also and the currency peg may collapse.

The currency weakens in this scenario because future monetization (seignorage) is required to support suddenly increased government commitments. The element that we leave out, of course, is how the Asian banks and large private companies got into trouble in the first place, and whether their troubles were aggravated by raising the interest rate. Once the private collapse begins, however, the standard KFG model translates the problems easily to a currency attack via the financing required to service government promises.

\section{CONCLUDING COMMENTS}

We have studied an extension of the KFG model and found that increasing the domestic-currency interest rate prior to a speculative attack, with no other policy adjustments, is never an effective exchange-rate defense. Indeed such a policy is self defeating - it always shortens the fixed-rate epoch. Promising to increase the interest rate after the attack (and actually doing so) is nearly always an effective way to defer the attackit is the interest rate defense. ${ }^{17}$

Before the attack, raising the rate increases debt service and draws in international reserves, but international reserves are a bad investment here-a fiscal drag that weakens the currency. We recognize that this can't be the whole story. Sensible policymakers and policy advisors worldwide are comforted uniformly by high reserve balances that have poor portfolio performance. There must, therefore, be some return to reserves that we are missing. We suspect the missing return might involve short-term capital stickiness that simply does not enter perfect capital mobility models like ours. Or it could be, for example, that raising the interest rate is the only way to defend the fixed exchange rate peg when there are doubts on its sustainability - a defense which might turn out to be successful ex post, if and when the doubts are dispelled by appropriate policy actions, good news or a shift in market sentiment.

${ }^{17}$ To keep the analysis simple, we have not studied the possibility of temporary interest rate responses to temporary shocks. The model is well-suited to such an investigation, but at the price of algebraic complexity. 


\section{A. Solving for the Pre-Collapse Debt Path}

After some substitutions equation (5) becomes:

$$
\dot{N}_{t}=\bar{r}\left(N_{t}-M\right)+\left(\bar{r}-r^{*}\right) \bar{S} R_{t}^{*}-\bar{S} \tau
$$

Since $M$ is constant during the fixed rate epoch, when $r$ is fixed, tracking $N$ requires that we keep track of reserves. Solving for $\bar{S} R_{t}^{*}$ in equation (8),

$$
\bar{S} R_{t}^{*}=\frac{\left.\overline{(r}-r^{*}\right) \bar{S}}{\theta}-\left(N_{t}-M\right)
$$

and plugging this expression into (A.1) gives:

$$
\dot{N}_{t}=r^{*}\left(N_{t}+\lambda\right)
$$

where $\lambda$ is given by equation (10). Equation (9) then directly follows from the integration of equation (A.2).

\section{B. Solving for the Post-Collapse Debt Path}

Reserves are set to zero and the interest rate is constant, equal to $\overrightarrow{\vec{r}}$. Simple manipulations of equations (2) and (5) give the following first-order differential equation for real debt:

$$
\dot{n}=\theta n^{2}-\left(\theta m-r^{*}\right) n-\dot{r} m-\tau
$$

with $m=\mu \exp (-\alpha \stackrel{=}{r})$ The right-hand-side of (A.3) is a second-order polynomial in $n$, with one unique positive root $v$, given by equation (13). This root can be characterized graphically as the point where the curve corresponding to the r.h.s. of (A.3) intersects the x-axis. The curve is strictly increasing at this point, implying that $n=v$ is an unstable solution. Hence, real debt goes to infinity if $n_{T}>v$ and converges to a negative level if $n_{T}<v$. We can rule out the first case on the ground that it violates the no-Ponzi game condition for the government, and rule out the second case by assumption. As a result the level of real debt must be equal to $v$ at the time of the collapse. In order to prove the inequalities in (14) and (15), note that increasing $\tau$ lowers the r.h.s. of (A.3) and so shifts its intersection with the X-axis to the right-i.e., this increases $v$. Differentiating the r.h.s. of (A.3) with respect to the interest rate shows that increasing $\vec{r}$ also increases $v$ provided that $\alpha(\vec{r}+\theta v)<1$. 


\section{References}

Bensaid, Bernard, and Olivier Jeanne, 1997, "The Instability of Fixed Exchange Rate Systems: When Raising the Interest Rate is Costly," European Economic Review 41, 1461-1478.

Berg, Andrew, 1999, "The Asia Crisis: Causes, Policy Responses and Outcomes," IMF WP/99/138.

Buiter, Willem, 1987, "Borrowing to Defend the Exchange Rate and the Timing and Magnitude of Speculative Attacks," Journal of International Economics, Vol. 23, 221-39.

Burnside, Craig, Eichenbaum, Martin and Sergio Rebelo, 1998, "Prospective Deficits and the Asian Currency Crisis," NBER WP 6758, October.

Cuthbertson, Keith, and Luis Galindo, 1999, "The Demand for Money in Mexico," The Manchester School 67, 154-166.

Daniel, Betty C., 2000, “A Fiscal Theory of Currency Crises," International Economic Review, forthcoming.

Drazen, Allan, 1999, "Interest Rate Defense Against Speculative Attack Under Asymmetric Information," University of Maryland, Dept. of Economics, processed.

Flood, Robert, and Peter Garber, 1984a, "Gold Monetization and Gold Discipline," Journal of Political Economy, Vol. 92, No.1, pp90-107.

___ 1984b, "Collapsing Exchange-Rate Regimes, Some Linear Examples," Journal of International Economics 17, 1-13.

Flood, Robert, and Nancy P. Marion, 1999, "Perspectives on the Recent Currency Crisis Literature," International Journal of Finance and Economics, Vol.4, no1, January.

—, 2000, "Self-fulfilling Risk Predictions: An Application to Speculative Attacks," Journal of International Economics, Vol 50, no. 1, February.

Furman, Jason and Joseph Stiglitz, 1998, "Economic Crises: Evidence and Insights from East Asia," Brookings Papers on Economic Activity 2, 1-135.

Goldfajn, Ilan, and Taimur Baig, 1998, "Monetary Policy in the Aftermath of Currency Crises: The Case of Asia," IMF Working Paper No.98/170 (Washington: International Monetary Fund). 
Jeanne, Olivier, and Andrew K. Rose, 1999, "Noise Trading and Exchange Rate Regimes," NBER Working Paper No. 7104.

Kraay, Aart, 1998, "Do High Interest Rates Defend Currencies During Speculative Attacks?," mimeo, World Bank.

Krugman, Paul, 1979, "A Model of Balance-of-Payments Crises," Journal of Money, Credit and Banking 11, 311-325.

Lahiri, Amartya, and Carlos A. Végh, 1999, "Delaying the Inevitable: Optimal Interest Rate Policy and BOP Crises," UCLA, Dept. of Economics, processed.

Lane, Timothy, Ghosh, Atish, Hamann, Javier, Phillips, Stevens, Schulze-Ghattas, Marianne, and Tsidi Tsikata, 1999, "IMF-Supported Programs in Indonesia, Korea, and Tailand, A Preliminary Assessment," Occasional Paper No.178 (Washington: International Monetary Fund).

Obstfeld, Maurice, 1986, "Rational and Self-fulfilling Balance of Payments Crises," American Economic Review 76, 72-81.

Sargent, Thomas and Neil Wallace, 1981, "Some Unpleasant Monetarist Arithmetic," Quarterly Review, Federal Reserve Bank of Minneapolis, Fall.

Werner, Alejandro, 1996, "Mexico's Currency Risk Premia in 1992-94: A Closer Look at the Interest Rate Differentials," IMF Working Paper 96/41.

Woodford, Michael, 1995, "Price Level Determinacy without Control of a Monetary Aggregate," Carnegie-Rochester Conference Series on Public Policy 43: 1-46. 